\title{
OS VINTE ANOS DO CURSO DE ENFERMAGEM NA UNIVERSIDADE FEDERAL DO PARANÁ E A TRAJETÓRIA DE SEUS EGRESSOS 1
}

FEDERAL UNIVERSITY OF PARANÁ NURSING COURSE TWENTIETH ANNIVERSARY AND ITS GRADUATES TRAUECTORY

\author{
Gláucia B. Seraphim ${ }^{2}$ \\ Verônica de A. Mazza ${ }^{3}$ \\ Liliana M. Labronici ${ }^{3}$ \\ Madalena Y. Nakayama ${ }^{3}$ \\ Valdirene Polonio ${ }^{4}$ \\ Evelise Mayer ${ }^{4}$
}

RESUMO: Trata-se de uma pesquisa retrospectiva realizada com os Egressos do Curso de Enfermagem da Universidade Federal do Paraná. Um breve levantamento dos registros em documentos como livros de ata e relatórios, e depoimentos que relatam fatos que erigiram a Enfermagem de hoje na UFPR. No período 1974 - 1994, o Curso graduou 467 Enfermeiros, aos quais foi encaminhado um questionário composto por questões abertas e fechadas, com a finalidade de avaliar a trajetória que os mesmos vêm percorrendo desde sua iniciação no mercado de trabalho. A amostra se constituiu de 62 Egressos que responderam ao questionário, sendo os dados qualitativos e quantitativos apresentados em quadros e tabelas. Os resultados oferecem subsídios para modificações curriculares e alerta para a necessidade de classificações e reformulações conceituais relativas ao ensino, à prática e à pesquisa em Enfermagem.

UNITERMOS: Prática profissional - Egressos - Enfermagem.

\section{INTRODUÇÃO}

O curso de Enfermagem da Universidade Federal do Paraná (UFPR) iniciou suas atividades em 1974, e foi o resultado de uma antiga pretensão dos enfermeiros paranaenses, em especial das enfermeiras do Hospital de Clínicas, da mesma Universidade. No momento em que se comemoram os vinte anos de

\footnotetext{
${ }^{1}$ Trabalho realizado pelo Grupo de Estudos sobre Metodologia da Assistência em Enfermagem (GEMA).

${ }^{2}$ Enfermeira. Doutor em Enfermagem. Professor Adjunto do Curso de Enfermagem da UFPR.

${ }^{3}$ Professores do Departamento de Enfermagem da UFPR.

${ }^{4}$ Alunas do Curso de Graduação em Enfermagem da UFPR.
} 
seu funcionamento, julgou-se importante realizar uma sondagem junto aos egressos, descortinando suas trajetórias durante este período.

Uma das grandes metas pretendidas pela comissão de organização das festividades dos 20 anos do Curso de Enfermagem da Universidade Federal do Paraná (UFPR) foi conhecer a caminhada de seus egressos. Localizar os 467 alunos que concluíram o curso até o final do ano de 1994 não foi tarefa fácil, considerando estarem os mesmos espalhados no Brasil, alguns em outros países e muitos exercendo atividades alheias à profissão. Mesmo assim, buscou-se por vários meios encontrar seus endereços, acreditando ser possível fazer um levantamento de suas atividades, suas realizações e mesmo as decepções ocorridas durante e após o término do curso, a fim de que tais informações viessem, de alguma forma, auxiliar-nos numa reflexão sobre os vinte anos de existência do Curso.

\section{REVISÃO BIBLIOGRÁFICA}

O ensino de enfermagem no Brasil, apesar de seus setenta anos de história, denota que a maioria das Escolas de Enfermagem ainda está em franca juventude, carecendo de avaliações e reforços contínuos, a fim de que possam bem cumprir a missão de preparar mais e melhor seus alunos. Ide et al. (1985) colocam que:

"é compromisso comum a docentes e profissionais do campro, avaliar até que ponto a curso de graduação em Enfermagem forma enfermeiras com bagagem teórico-prática suficiente e adequada para enfrentarem a realidade profissional.

Apesar da escassez de trabalhos realizados com egressos e de forma específica com egressos de enfermagem, sabe-se que eles são o produto e/ou resultado do esforço de docentes, dos administradores dos cursos, da plêiade de profissionais que estão nos campos de prática, da comunidade, das famílias e dos clientes. Bem preparados ou não, eles estão aplicando aquilo que aprenderam durante sua vida estudantil, ajudando a clientela a prevenir, manter e recuperar suas condições de saúde. Barroso, M.G.T; Costa,L.B.; Varela, Z.V. (1992) enfatizam que: "o acompanhamento aos egressos tem revelado fatos que podem ser indicadores positivos do êxito alcançado pelos alunos".

Lima (1993) destaca a importância da relação entre a formação do enfermeiro e a sua prática profissional, baseada em estudos advindos da vivência com os egressos da Escola de Enfermagem da Universidade Federal do Rio Grande do Sul quando no exercício de sua prática em um hospital da cidade de Porto Alegre. A mesma autora reconhece que o ensino de enfermagem desenvolvido ao longo do curso está centrado na assistência voltada para aspectos assistenciais e, quando os profissionais vão para a prática, tal esforço 
é inexistente. As situações vivenciadas no campo de trabalho são por vezes muito diferentes daquelas tidas durante o decorrer do curso.

As várias modificações curriculares no Curso de Enfermagem da UFPR, efetivadas no período dos vinte anos estudados, os debates, os acréscimos e a qualificação de seu corpo docente, as imposições conjunturais sócio-políticoeconômico-culturais que permearam as Universidades e a sociedade brasileira nesse período e suas implicações sobre a área da saúde, bem como o desejo de colaborar para a melhoria de ensino de enfermagem, incentivaram as autoras na realização da presente pesquisa, para a qual formularam os objetivos a seguir.

\section{GERAL:}

- Contribuir para o levantamento histórico do Curso de Enfermagem da Universidade Federal do Paraná (UFPR).

\section{ESPECÍFICOS:}

- Cadastrar os egressos do curso de Enfermagem da UFPR.

- Verificar a trajetória profissional dos egressos do curso de Enfermagem da UFPR.

- Registrar fatos importantes ocorridos durante a realização do Curso de Enfermagem da UFPR segundo a percepção dos seus egressos.

- Selecionar sugestões apresentadas pelos egressos do Curso de Enfermagem da UFPR que poderão contribuir para a melhoria do ensino na atualidade.

\section{METODOLOGIA}

Trata-se de um trabalho retrospectivo, tendo como universo pesquisado os egressos do Curso de Enfermagem da UFPR, levantados através do livro de registro de diplomas da coordenação do curso, num total de 467 graduados, do início do curso até o final do ano de 1994. O instrumento foi um questionário composto por uma questão identificadora, seguida de dados relacionados à formação de pós-graduação, empregos, família e outras atividades da área profissional. Duas questões abertas completam o questionário, interrogando os egressos sobre os fatos significativos vividos durante o curso e solicitando sugestões para a melhoria do mesmo.

Os endereços foram obtidos através de contatos com os locais de trabalho, registros no Conselho Regional de Enfermagem (COREN-Pr), Associação Brasileira de Enfermagem (ABEn-Seção-Pr) e informações de colegas.

Os resultados quantitativos foram organizados em gráficos e tabelas sendo que os dados qualitativos foram colocados em quadros, após sua categorização. 


\section{APRESENTAÇÃO E DISCUSSÃO DOS RESULTADOS}

\section{DADOS QUANTITATIVOS.}

A análise quantitativa dos dados, baseada em números absolutos e percentuais, é apresentada a seguir, em gráficos e tabelas.

TABELA 1 - NÚMERO DE ALUNOS MATRICULADOS, FORMANDOS E PERCENTAGEM DE EVASÃO DO CURSO DE ENFERMAGEM UFPR - 1975 A 1994.

\begin{tabular}{cccc}
\hline ANO & MATRICULADOS & FORMANDOS & $\%$ de EVASÄO \\
\hline 1975 & 040 & - & - \\
\hline 1976 & 040 & - & - \\
\hline 1977 & 040 & - & - \\
\hline 1978 & 040 & 010 & 75 \\
\hline 1979 & 040 & 013 & 67 \\
\hline 1980 & 040 & 027 & 32 \\
\hline 1981 & 040 & 007 & 82 \\
\hline 1982 & 040 & 042 & - \\
\hline 1983 & 040 & 035 & 12 \\
\hline 1984 & 040 & 033 & 17 \\
\hline 1985 & 050 & 040 & 20 \\
\hline 1986 & 050 & 047 & 06 \\
\hline 1987 & 050 & 026 & 48 \\
\hline 1988 & 050 & 031 & 38 \\
\hline 1989 & 060 & 038 & 37 \\
\hline 1990 & 055 & 019 & 65 \\
\hline 1991 & 055 & 025 & 54 \\
\hline 1992 & 055 & 033 & 40 \\
\hline 1993 & 055 & 021 & 62 \\
\hline 1994 & 055 & 020 & 64 \\
\hline TOTAL & 935 & 467 & 50 \\
\hline
\end{tabular}

FONTE: Coordenação do Curso de Enfermagem da UFPR.

Relacionando o número de entrada com o número de formandos numa contagem de quatro em quatro anos (tempo médio para conclusão do curso), obtivemos um percentual para cada ano e, por final, relacionando os números totais de matriculados e de formandos, concluimos que nos 20 anos do curso de Enfermagem da UFPR o percentual de evasão foi em torno de $50 \%$, ou seja, 468 alunos matriculados não continuaram no curso. 


\section{GRÁFICO 1 - VARIAÇÃO DO NÚMERO DE FORMANDOS DO CURSO DE ENFERMAGEM DA UFPR, NO PERIOODO DE 1978 A 1994.}

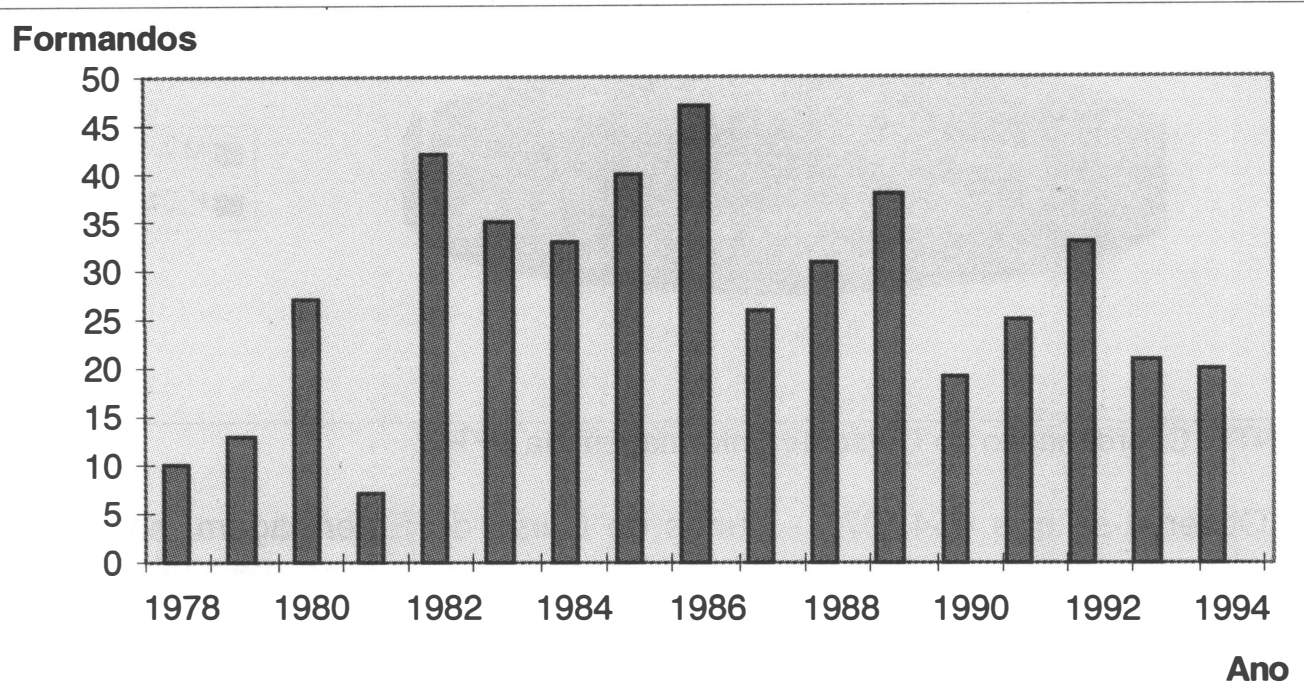

FONTE: Coordenação de Enfermagem da UFPR.

A representação gráfica da Tabela 1 oferece uma visualização da grande variabilidade do número de formandos, apresentando uma maior elevação nos anos de 1982 e 1988. A taxa de evasão (50\%), não é fenômeno peculiar deste curso e do periodo analisado. A Enfermagem vem enfrentando este problema em todo o Brasil, e se sente desafiada a manter seus alunos nos bancos escolares até o final do Curso. Para tanto, vem apostando em diversas estratégias: reformas ou ajustes curriculares, qualificação de docentes (pósgraduação, congressos, seminários), compromisso com atividades de extensão, ampliação das linhas de pesquisas e mais politização, numa tentativa de apresentar aos discentes uma profissão promissora, humana e necessária. 


\section{GRÁFICO 2 - PERCENTAGEM DE ALUNOS MATRICULADOS NO CURSO DE ENFERMAGEM, DE ACORDO COM O SEXO.}

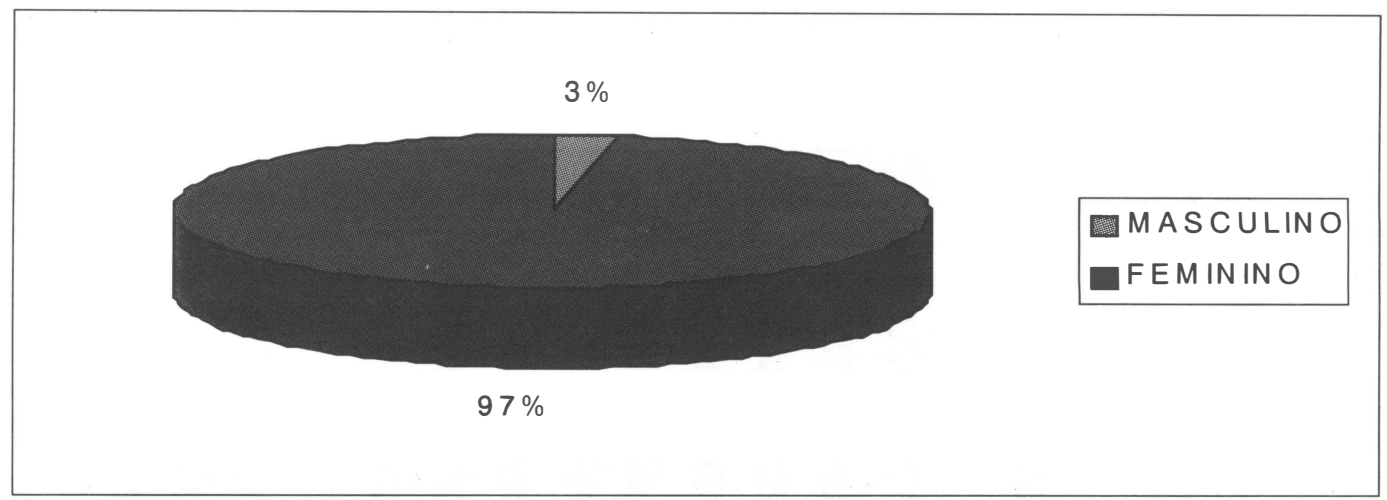

FONTE: Coordenação do Curso de Enfermagem da UFPR.

Observa-se que 454 (97\%) alunos do Curso de Enfermagem, em 20 anos, são do sexo feminino e apenas $13(3 \%)$ pertencem ao sexo masculino, fato que vai de encontro com as estimativas apuradas em outros locais do Brasil. Estes dados evidenciam que a profissão de Enfermagem, apesar de requisitar de seus membros qualidades físicas, intelectuais e humanísticas excepcionais, ainda não oferece compensações financeiras e de reconhecimento social que sirvam como atrativos para o fluxo de um maior número de candidatos do sexo masculino.

\section{GRÁFICO 3 - PERCENTAGEM DE ALUNOS EGRESSOS DE ACORDO COM RESPOSTAS DOS QUESTIONÁRIOS.}

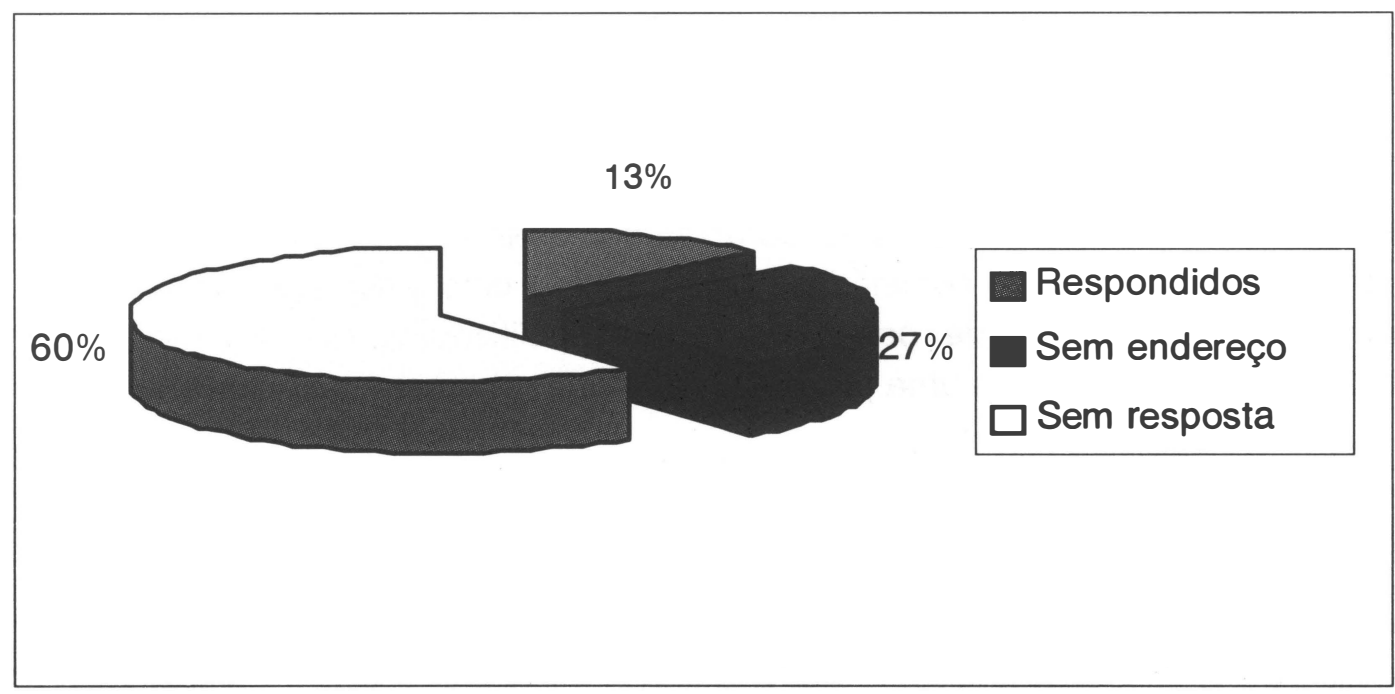


O gráfico apresentado evidencia que, dos 467 egressos do Curso de Enfermagem da UFPR, até o ano de 1994, apenas $62(13 \%)$ responderam aos questionários. Quanto aos, demais, 128 (27\%) não foram localizados e 277 $(60 \%)$ não responderam. É importante salientar, entretanto, que, neste último grupo, estão incluídos alguns questionários devolvidos pelo correio, cujo destinatário não foi encontrado.

\section{GRÁFICO 4 - TEMPO DISPENDIDO PARA CONCLUSÃO DO CURSO NA POPULAČÃO DOS EGRESSOS DO CURSO DE ENFERMAGEM DA UFPR., DE 1978 A 1994.}

$\mathrm{N}$ o de anos

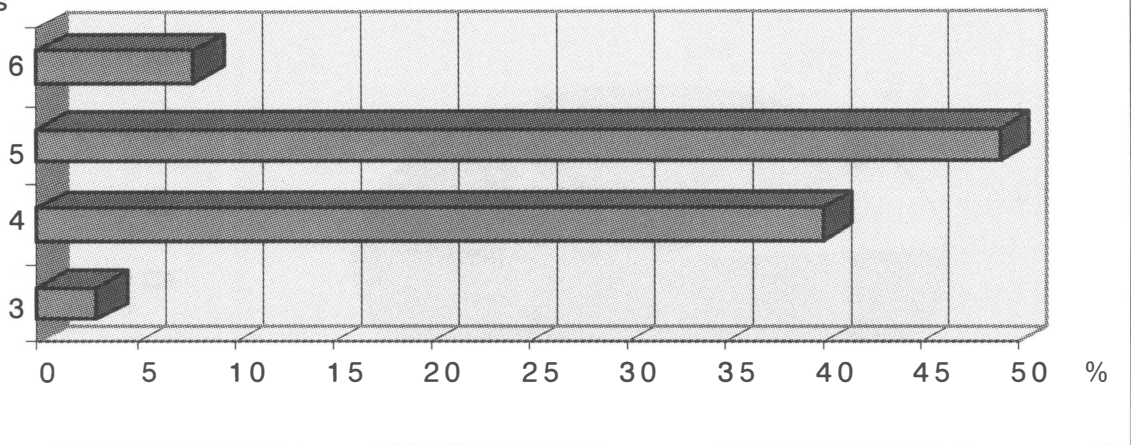

Parte significativa (40\%) dos egressos do Curso de Enfermagem da UFPR concluiu o curso dentro do prazo normal estipulado pelo currículo, que é de quatro anos. Acredita-se que aqueles que responderam ter concluído o curso em três anos foram alunos transferidos ou que fizeram reaproveitamento de curso. É curioso, também, observar que um número expressivo de alunos $(49 \%)$ só concluiu a graduação depois do prazo estipulado.

\section{GRÁFICO 5 - DISTRIBUIÇÃO GEOGRÁFICA DOS EGRESSOS DO CURSO DE ENFERMAGEM DA UFPR FORMADOS NO PERIODO DE 1978 A 1994.}

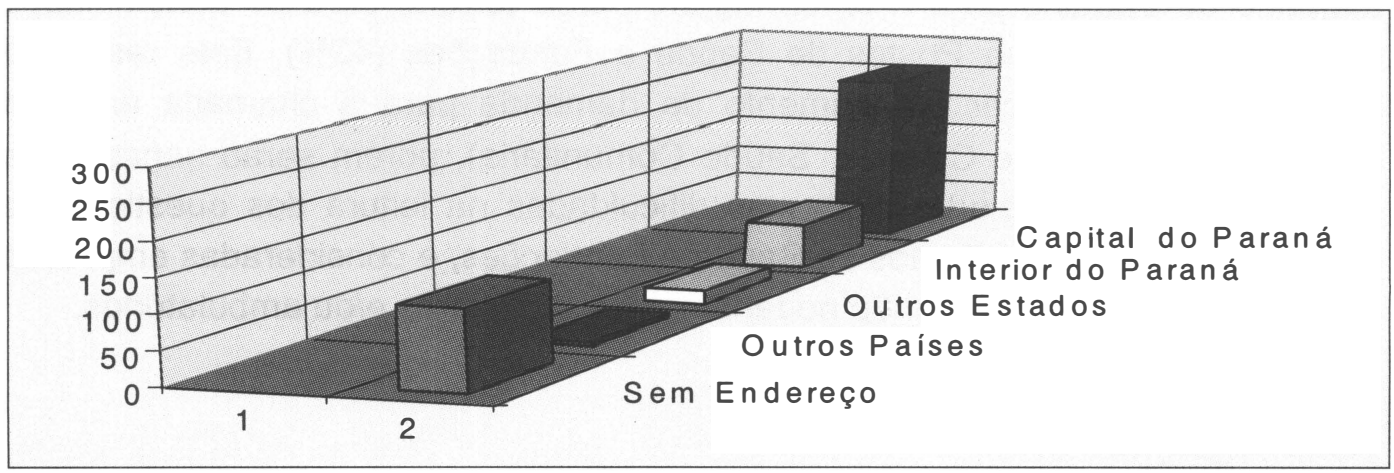

O Gráfico 5 nos oferece um panorama da localização atual de nossos egressos. É importante ressaltar que 118 ex-alunos (27\%) não foram 
consultados, por não se ter o endereço. Dos restantes 349, 255 atuam em Curitiba (54\%), capital do Paraná, 68 (14\%), foram para o interior do Paraná, 20 (4\%) locomoveram-se para outros estados, restando 6 (1\%) que imigraram para outros Países (Chile, Argentina, Alemanha, USA).

\section{GRÁFICO 6 - EGRESSOS DO CURSO DE ENFERMAGEM DA UFPR SEGUNDO O ATUAL LOCAL DE TRABALHO-1994.}
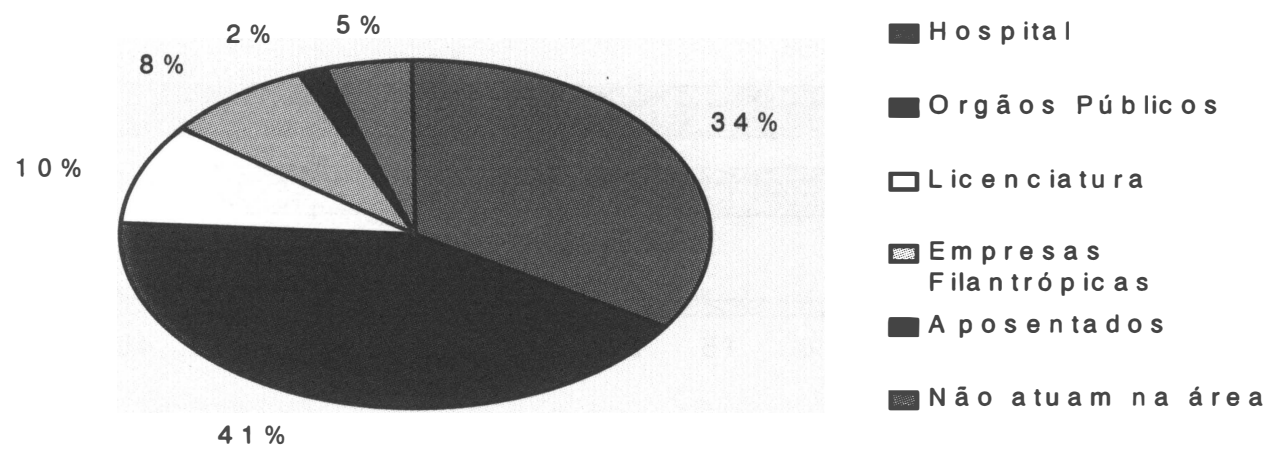

Analisando os 62 questionários respondidos, verificamos que 21 dos egressos de Enfermagem da UFPR (34\%) trabalham em Hospitais, 26 (42\%) em instituições, postos e centros de saúde e fundações autárquicas do Setor Público, 6 (10\%) atuam em Escolas de $1^{\circ}$ e 20 Graus,5 (8\%) em empresas filantrópicas, 1 (2\%) é aposentado e $3(5 \%)$ não atuam na área de enfermagem. A área hospitalar (34\%), que tradicionalmente tem tido prevalência como mercado de trabalho para a enfermagem, perde terreno para os denominados órgãos públicos, como Postos de Saúde e Fundações (42\%). Este resultado permite-nos reconhecer um aumento de demanda para a chamada área da Saúde Pública (Saúde Coletiva, Saúde Comunitária), porém serão necessárias pesquisas mais detalhadas dadas as dificuldades na leitura dos questionários onde foram agrupados Postos de Saúde e Fundações, e consideradas empresas filantrópicas separadas quando poderiam ser hospitalares e/ou ambulatórios. 


\section{GRÁFICO 7 - TEMPO DE PERMANÊNCIA NO TRABALHO PROFISSIONAL DOS EGRESSOS DE ENFERMAGEM DA UFPR, DEPOIS DA GRADUAÇÃO.}

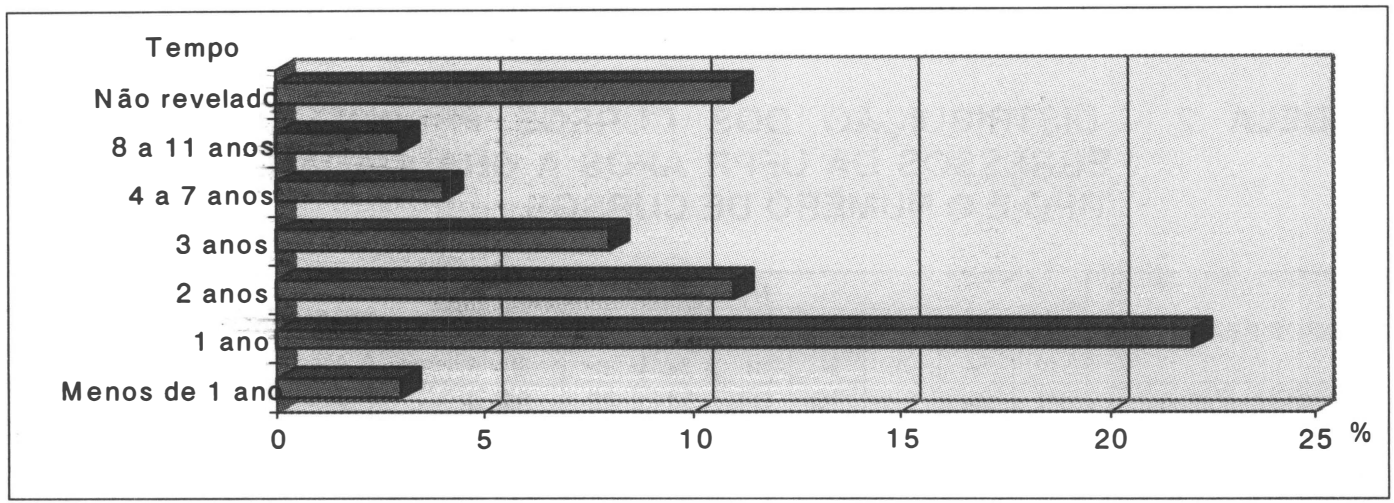

O tempo de permanência no trabalho dos 62 Enfermeiros egressos apresentado no gráfico acima retrata que 3 egressos $(5 \%)$ permaneceram menos de um ano no mesmo serviço, $22(35 \%)$ o fizeram por um ano, $11(18 \%)$ em dois anos, 8 (13\%) em três anos, $4(6 \%)$ não mudaram de trabalho por um período de quatro a sete anos. Ressalta-se ainda que 3 dos egressos (5\%) permaneceram no mesmo trabalho de oito a onze anos e 11(18\%) não relataram nos questionários o tempo que permaneceram no trabalho. Inúmeras são as razões que levam os profissionais a mudarem de local de trabalho em curto espaço de tempo. Na maioria das vezes estas mudanças são devidas à baixa remuneração e carga horária excessiva, gerando insatisfação e levando a mudanças freqüentes. Tal rotatividade é pouco recomendável para os serviços, trabalhadores e clientes; é preciso que se observem os efeitos negativos dela, pois a relação terapêutica fica comprometida.

\section{GRÁFICO 8 - CURSOS DE ESPECIALIZAÇÃO MAIS PROCURADOS PELOS EGRESSOS DO CURSO DE ENFERMAGEM DA UFPR.}

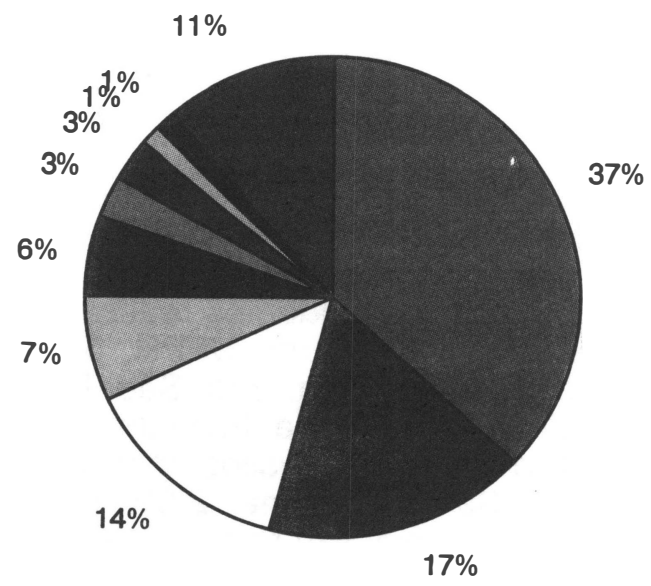

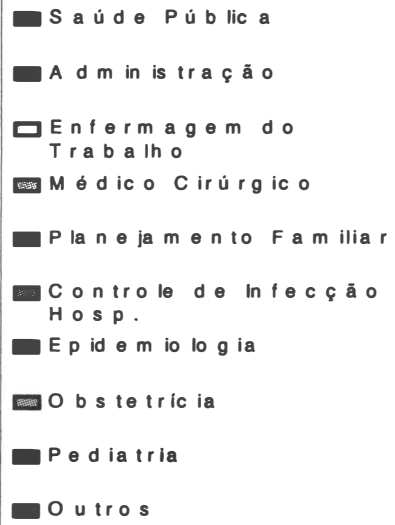

ש $\mathrm{S}$ ú $d e P$ ú b lic a

A d $m$ in is $\operatorname{trac} a \tilde{o}$

ש E f erm a gem do

Tra b a tho

a d d ic o C irúrg ic o

- P la $n$ eja mento Fa m iliar

Co $n$ tr

E $p$ id $\theta \mathrm{m}$ io $10 \mathrm{~g}$ ia

Obstericia

Pediatria

O u tros 
Difícil se torna identificar até que ponto a demanda corresponde à oferta dos cursos, ao desejo do candidato ou ainda à vontade dos enfermeiros em prosseguir nas lides escolares. De qualquer forma, sabe-se que os cursos da área hospitalar são os mais procurados, em especial, os que oferecem alta especialização.

\section{TABELA 2 - DISTRIBUIÇÃO DOS CURSOS FREQÜENTADOS PELOS EGRESSOS DA UFPR APÓS A GRADUAÇÃO, SEGUNDO O TIPO E O NÚMERO DE CURSOS.}

\begin{tabular}{|c|c|c|c|c|c|c|c|c|c|c|c|c|c|c|}
\hline \multirow{3}{*}{ CURSOS REALIZADO } & \multicolumn{6}{|c|}{ NÚMERO } & \multicolumn{2}{|c|}{ DE } & \multicolumn{2}{|c|}{ CURSOS } & \multirow{2}{*}{\multicolumn{2}{|c|}{ Incomp. }} & \multirow{2}{*}{\multicolumn{2}{|c|}{ TOTAL }} \\
\hline & \multicolumn{2}{|c|}{01} & \multicolumn{2}{|c|}{02} & \multicolumn{2}{|c|}{03} & \multicolumn{2}{|c|}{ Nenhum } & \multicolumn{2}{|c|}{ Cursando } & & & & \\
\hline & $n$ & $\%$ & $n$ & $\%$ & $n$ & $\%$ & $n$ & $\%$ & $n$ & $\%$ & $n$ & $\%$ & $n$ & $\%$ \\
\hline ESPEC & 21 & 34 & 10 & 16 & 07 & 11 & 20 & 31 & - & - & 01 & 2 & 58 & 94 \\
\hline MESTRADO & & - & - & - & - & - & - & - & 01 & 2 & - & - & 01 & 02 \\
\hline OUTROS CURSOS & 01 & 02 & - & - & - & - & - & - & - & 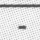 & 01 & 2 & 01 & 04 \\
\hline
\end{tabular}

Nesta Tabela constata-se que $34 \%$ dos egressos do Curso de Enfermagem da UFPR fizeram um curso de especialização, $16 \%$ tem duas especializações e $11 \%$ têm até três especializações. Porém, é de se notar o percentual (31\%) dos que não têm nenhuma especialização. A freqüência aos cursos de mestrado ainda é pequena $(2 \%)$ e o número de enfermeiros que buscam outros cursos de graduação se aproxima dos $4 \%$.

\section{GRÁFICO 9 - LOCAL DE REALIZAÇÃO DOS CURSOS DE ESPECIALIZAÇÃO DOS EGRESSOS DO CURSO DE ENFERMAGEM DA UFPR.}
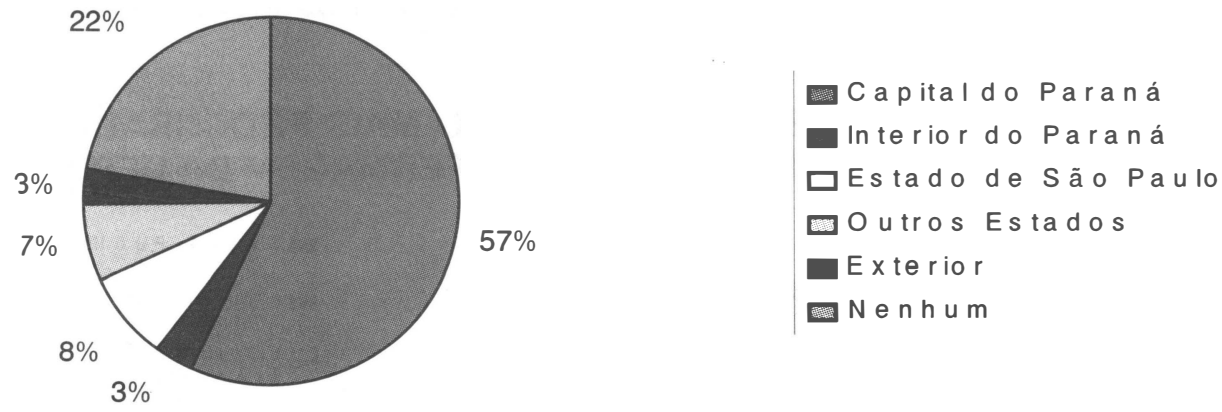

No Gráfico 9, observamos que 51 (57\%) dos respondentes realizaram seus cursos de especialização em Curitiba, sendo $13(14 \%)$ na UFPR, 5 (6\%) na PUC-Pr e 33 (37\%) em outras instituições de Curitiba. Em São Paulo, os egressos realizaram 7 cursos $(8 \%)$, incluindo-se aí o da Faculdade de São Camilo entre outras. Outros Estados procurados pelos egressos para realizarem sua especialização foram 6 (7\%): 2,3\% em Santa Catarina, 2,3\% no Distrito Federal, 1,2\% no Rio de Janeiro e 1,2\% em Rondônia. Em relação ao exterior, 3 (3\%) fizeram sua especialização no Chile, na Alemanha e nos EUA. Não se 
considerou neste gráfico o número de especializações por pessoa, mas sim o número total de especializações feitas e já referidas no Gráfico 8 e na Tabela 2.

\section{DADOS QUALITATIVOS}

A análise das questões abertas acrescenta um forte componente avaliador deste percurso, além de oferecer críticas e sugestões para as reformulações curriculares. Interessante foi também o reconhecimento de que muitas críticas e sugestões apresentadas já vinham sendo detectadas pelo corpo docente, discente e administrativo e providenciadas as necessárias modificações. Confirmam-se, portanto, as palavras de Dilascio (1970): "o estudante ao término do curso, não é um produto acabado..."daí o compromisso do docente em acompanhá-lo na nova carreira profissional, tomando o seu desempenho tendo-o como mais um parâmetro crítico para melhorar a formação profissional.

$\mathrm{Na}$ seqüência (Quadros 1 e 2) passamos a considerar as respostas às questões abertas sobre as impressões dos egressos vividas durante o curso e suas sugestões para melhorar o processo.

Para isso, foram analisadas as respostas e distribuições em três categorias básicas, em torno das quais foram emitidas opiniões. São elas: a categoria professor, a categoria curso e a categoria estágios.

\section{QUADRO 1 - CATEGORIZAÇÃO DAS RESPOSTAS QUANTO A IMPRESSÃO MAIS MARCANTE VIVENCIADA PELOS RESPONDENTES DURANTE O CURSO.}

\begin{tabular}{|c|c|c|}
\hline CATEGORIA & CATEGORIA & CATEGORIA \\
\hline PROFESSOR & ESTÁGIO & CURSO \\
\hline $\begin{array}{l}\text { - Bom preparo aos alu- } \\
\text { nos } \\
\text { - Companheiros } \\
\text { - Incentivadores } \\
\text { - Paternalista } \\
\text { - Ausentes no Estágio } \\
\text { - Deveriam ser mais } \\
\text { - exigentes } \\
\text { - Desconhecem as políti- } \\
\text { cas de saúde } \\
\text { - Pouco preparo dos } \\
\text { - Pocentes } \\
\text { professores que acom- } \\
\text { panhavam os alunos no } \\
\text { estágio }\end{array}$ & $\begin{array}{l}\text { - Administração no pronto- } \\
\text { atendimento e Pediatria } \\
\text { - Psiquiatria infantil } \\
\text { - Saúde da mulher e criança } \\
\text { - Aulas práticas com cirur- } \\
\text { gias contaminadas } \\
\text { - O cuidado do paciente } \\
\text { oncológico } \\
\text { - Prática insuficiente } \\
\text { - Insegurança para enfrentar } \\
\text { - I vida profissional } \\
\text { - Insegurança inicial, pondo } \\
\text { em dúvida a escolha da } \\
\text { profissão } \\
\text { - Boa recepção no Hospital } \\
\text { de Clínicas } \\
\text { - Primeira punção venosa } \\
\text { - quase desisto do Curso) } \\
\text { - Contato com os pacientes } \\
\text { - Sofrimento dos pacientes }\end{array}$ & $\begin{array}{l}\text { - Que a Enfermagem era muito mais } \\
\text { do que foi transmitido no curso } \\
\text { - Comentários pejorativos por parte } \\
\text { - dos estudantes de Medicina } \\
\text { - Que o Curso ofereceu bastante } \\
\text { bagagem teórica, técnica e co- } \\
\text { nhecimento } \\
\text { - O respeito que se tem pelo enfer- } \\
\text { meiro } \\
\text { - Pouca relação com a equipe de } \\
\text { enfermagem } \\
\text { - A consulta de enfermagem em } \\
\text { pré-natal de baixo risco } \\
\text { - Currículo defasado } \\
\text { - Identificação profissional possibi- } \\
\text { litada } \\
\text { - Desvalorização da profissão } \\
\text { - A prática assistencial } \\
\text { - O início e o fim do curso } \\
\text { - Falta de prática na licenciatura } \\
\text { - Participação na extensão e na } \\
\text { reforma curricular. }\end{array}$ \\
\hline
\end{tabular}


As impressões mais marcantes vivenciadas pelos egressos apresentadas nas três categorias do quadro acima podem ser resumidas em aspectos positivos e negativos, e intermediários.

- Professores: apontados aspectos positivos: preparam bem os alunos, são companheiros, incentivadores e acompanhantes dos alunos nos estágios. Aspectos intermediários: o fato de serem paternalistas e pouco exigentes. Aspectos negativos: ausentes no estágio, desconhecedores das políticas de saúde e sem preparo suficiente.

- ESTÁGIOS: nesta categoria foram destacadas como impressões positivas mais marcantes: os estágios em Administração no Pronto-Atendimento e Pediatria, o estágio em Psiquiatria Infantil, a questão da saúde da mulher e da criança, e a boa recepção no Hospital de Clínicas. O sofrimento e o contato com pacientes, em especial os oncológicos, podem ser classificados como aspectos intermediários, sendo que a insegurança inicial e as aulas práticas pôr vezes insuficientes foram pontos destacados nesta categoria julgados como negativos.

- CURSo: aqui foram feitas observações positivas como: a bagagem oferecida pelo curso, 0 respeito e a identificação profissional sempre ressaltados, a possibilidade de participar em rogra de extensão, vivenciar um processo de reforma curricular, a prática assistencial, e a realização de consultas de enfermagem em ambulatório de pré-natal e baixo risco. Observações intermediárias foram em relação ao currículo defasado, e negativas no que diz respeito à desvalorização profissional sentida durante o relacionamento com os alunos do curso de medicina, a pouca relação com a equipe de enfermagem e a ausência da oferta de licenciatura para os graduandos.

\section{QUADRO 2 - CATEGORIZAÇÃO DAS RESPOSTAS QUANTO AS SUGES- TÕES PARA MELHORIA DO CURSO.}

\begin{tabular}{|c|c|c|}
\hline CATEGORIA & CATEGORIA & CATEGORIA \\
\hline $\begin{array}{c}\text { PROFESSORES- } \\
\text { PESQUISA-FORMAÇÃO }\end{array}$ & ESTÁGIOS & CURSO \\
\hline $\begin{array}{l}\text { - Melhorar o nivel técnico e } \\
\text { cientifico dos professores } \\
\text { - Reciclagem dos professo- } \\
\text { res } \\
\text { - Integrar os professores do } \\
\text { básico e do profissional } \\
\text { - Estimular a pesquisa } \\
\text { - Estimular a participação na } \\
\text { extensão } \\
\text { - Estimular a realização de } \\
\text { cursos de especialização e } \\
\text { mestrado } \\
\text { - Estudar teorias de enferma- } \\
\text { gem, processo e consulta } \\
\text { de enfermagem } \\
\text { - Utilizar dados da prática em } \\
\text { trabalhos científicos }\end{array}$ & $\begin{array}{l}\text { - Melhorar o estágio em } \\
\text { obstetrícia e emergência } \\
\text { - Aumentar a carga horária } \\
\text { de Saúde Pública } \\
\text { - Acrescentar estágio em } \\
\text { Unidade de Terapia Inten- } \\
\text { siva } \\
\text { - Ampliar as opções para } \\
\text { estágios } \\
\text { - Maior atuação dos alunos } \\
\text { nos campos } \\
\text { - Trabalhar junto à comuni- } \\
\text { dade } \\
\text { - Aumentar a carga horária } \\
\text { nos estágios } \\
\text { - Mais aulas práticas } \\
\text { - Oferecer oportunidades } \\
\text { para a prática da lide- } \\
\text { rança, tomada de deci- } \\
\text { são, trabalho em equipe e } \\
\text { gerenciamento de uni- } \\
\text { dade }\end{array}$ & $\begin{array}{l}\text { - Melhorar o conteúdo de doenças } \\
\text { transmissiveis e imunizaçōes } \\
\text { - Formar profissionais críticos e } \\
\text { - ativos } \\
\text { - Aumentar o conteúdo de epide- } \\
\text { miologia e infeção hospitalar } \\
\text { - Condensar disciplinas } \\
\text { - Prover a integração docente } \\
\text { assistencial } \\
\text { - Reforçar o ensino dos problemas } \\
\text { éticos relacionados à engenharia } \\
\text { genética } \\
\text { - Aumentar o curso para cinco } \\
\text { anos } \\
\text { - Atualizar a prática de ensino com } \\
\text { a realidade } \\
\text { - Acrescentar informações sobre } \\
\text { - hematologia e hemoterapia } \\
\text { - Acrescentar a licenciatura } \\
\text { reentivar os alunos a aproveita- } \\
\text { rem a experiência do professor }\end{array}$ \\
\hline
\end{tabular}


- Em relação à categoria PROFESSOR - PESQUISA - FORMAÇÃo observa-se que os oito pontos ressaltados na primeira coluna deste quadro se constituíram em plataformas pretendidas pelos coordenadores e chefes de departamento que ocuparam estes cargos durante estes vinte anos. A intensificação no preparo de seus docentes comprovada não só pelo incremento da pós-graduação como pela participação em cursos de aperfeiçoamento e atualização, as tentativas de integração com o ciclo básico, as propostas das várias reformulações curriculares, o incentivo à pesquisa e a participação dos programas de extensão e ainda a incorporação de temas sobre teorias de Enfermagem nos planos de ensino e seu necessário aprofundamento, evidenciam a tentativa de atendimento aos anseios apresentados.

- Na segunda categoria do Quadro 2 - ESTÁGIOS observou-se que algumas das reivindicações têm sido atendidas em parte e outras em sua totalidade. As questões de estágio em unidade de terapia intensiva (UTI), obstetrícia e emergência independem da vontade dos membros do corpo docente. Há que se esperar a abertura do Hospital Vitor Amaral e do Pronto-Socorro Municipal. que certamente viabilizarão um estágio mais satisfatório. A questão do estágio em UTI tem sido atendida em nível de especialização.

- CuRso: acredita-se que paulatinamente vem se tentando atender às sugestões apresentadas pelos egressos. Assim, a última reformulação curricular demonstra a disposição das disciplinas em dez (10) períodos, condensando disciplinas e tentando integrá-las. $O$ incentivo à formação pedagógica e à pesquisa, a participação discente em programas de monitoria, bolsas-trabalho e iniciação científica, e a criação de grupos de pesquisa têm se apresentado como medidas iniciais das profundas e necessárias mudanças no curso em tela.

\section{CONCLUSÃO}

Conhecer a trajetória dos egressos do Curso de Enfermagem da UFPR foi um trabalho envolvente, porém de forma alguma conclusiva. Pelo contrário, esta pesquisa impulsiona a comunidade acadêmica a pensar em formas de dar continuidade a esse conhecimento de maneira mais completa e sistemática. A necessidade de atualização constante do cadastro dos egressos, seu acompanhamento contínuo, a realização de encontros científicos, são medidas que devem ser implementadas, se se pretende a formação de mais e melhores enfermeiros, capazes de contribuir para a elevação dos níveis de saúde da população.

A análise crítica dos erros do passado e as propostas de mudanças baseadas na opinião daqueles que viveram o processo devem ser encaradas de forma contributiva, necessária e urgente. 
Reivindicações que ainda não puderam ser atendidas devem ser reiniciadas com novo vigor, acrescidas de novos recursos, novos conhecimentos e com a mesma naturalidade com que foram atendidos alguns dos problemas levantados. Questões estruturais (planta física, laboratórios, biblioteca, etc) e principalmente a manutenção de um corpo docente maior e qualitativamente adequado, que dificilmente poderão ser atendidas face às crises pelas quais passam as universidades brasileiras, não podem ser minimizados. Também as reformas no ensino e a necessária integração inter e intradisciplinar, associadas aos problemas decorrentes da setorialização dentro da própria UFPR, são processos de lenta solução e de difícil implantação. Julgamos, entretanto, após este estudo, que tais desafios devem ser enfrentados, e que as buscas para o aperfeiçoamento do ensino, da pesquisa e da extensão devem ser prioridades da vida acadêmica. De qualquer forma, a realização profissional dos alunos e a satisfação da clientela atendidas por eles ao longo de sua formação, devem servir como estímulo de um processo analítico deste e de outros Cursos de Enfermagem.

ABSTRACT: This is a retrospective research with nurses graduated from the Federal University of Paraná (UFPR). A brief review of records such as meetings minutes, reports, and interviews documented the facts that built nursing from 1974 to 1994 at UFPR. The program graduated 467 nurses, to whom a questionnaire, containing open and closed questions, was sent. The sample was constituted of 62 graduates who answered the questionnaire. Qualitative and quantitative outcomes are presented in tables, providing support to curriculum changes and offering an alert to the need of conceptual clarification regarding teaching, practice and nursing research.

KEYWORDS: Professional practice - Graduates - Nursing. 


\section{BIBLIOGRAFIAS}

1. BARDIN, L. Análise de Conteúdo. Trad. Luís Antero Rito e Augusto Pinheiro. Lisboa: Setenta, 1977. 223p.

2. BARBIER, René. Pesquisa - Ação na Instituição Educativa. Rio de Janeiro: Zahar, 1985.

3. BARROSO, M.G.T; COSTA, LB.; VARELA,Z.V. Documentário: Dez Anos do Curso de Enfermagem - UFC. Ed. Imprensa Universitária, Fortaleza - CE. 1992. p. 114.

4. CAMPEDELLI, M.A. Org. Processo de Enfermagem na Prática. São Paulo: Ática, 1989. 136p.

5. DILASCIO, C.M.D. Integração do recém-nascido na vida profissional. R. Bras. Enferm., Rio de Janeiro, v. 23 n. 2 p. 57 - 72, jan./jun., 1970.

6. GEORGE, J.B. "et al". Teoria de Enfermagem: os fundamentos para a prática profissional. Porto Alegre: Artes Médicas, 1993.

7. HORTA, W.A. Contribuição para uma Teoria de Enfermagem. R. Bras. de Enferm. Rio de Janeiro, 1967.

8. Processo de Enfermagem: Fundamentação e Aplicação. R. Enferm. Novas Dimensões. São Paulo, v.1, n.1, p.10 - 16, 1975.

9. IDE, C.A.C.; PADILHA, K.G.; PIERIN, A.M.G.; MAEDA, S.T. O seguimento do graduado em enfermagem. R. EsC. Enferm. USP. São Paulo, v. 19 n. 3 p. 195$211,1985$.

10. KOCH, R.M.; OKA, L.N. Processo de Enfermagem: Avaliação feita pelos Alunos do Departamento de Enfermagem da UCP. R. Bras. de Enferm. Brasília, v.30, p.274 - 285, 1977.

11. LIMA, M.A.D. da S. A Formação do Enfermeiro e a Prática Profissional: qual a relação? Porto Alegre: PUCRS, 1983. Dissertação (Mestrado em Educação) - Faculdade de Educação, Pontifícia Universidade Católica do Rio Grande do Sul, 1983.

12. Ensino de Enfermagem: Retrospectiva, Situação Atual e Perspectivas. R. Bras. Enferm. Brasilia, v, 47, n.3, p. 270-277, jul./set., 1994. 
13. MEIRELLES, A.S. V. O Quê e o Porquê do Ensino da Realidade Assistencial em Enfermagem. R. Esc. de Enferm. USP. São Paulo: 1987.

14. NAKAMAE,D.D. Mudanças no perfil do estudante da EEUSP em quinze anos 1973 a 1988. R. ESC. Enferm. USP, v.26, n.1, p 9-16, mar., 1992.

15. TRIVIÑOS, N.S. Augusto. Introdução à Pesquisa em Ciência Sociais. São Paulo: ATLAS, 1987. 